\title{
Dietary variety stimulates appetite in females but not in males
}

\author{
WILLIAM W. BEATTY \\ North Dakota State University, Fargo, North Dakota 58105
}

\begin{abstract}
Male and female college students ate as much as they wished of either one or three of their favorite ice cream flavors. Females who were allowed to consume three flavors ate more ice cream than those who could only eat one flavor. By contrast, ice cream consumption by males was unaffected by the number of flavors available. Human females have stronger inhibitions about eating than males, but these inhibitions can be overridden by presentation of a variety of palatable foods, especially when satiety mechanisms are already operating, as at the end of a meal.
\end{abstract}

Recent research suggests that increasing variety in a diet of palatable foods increases intake. When different foods are presented in a succession of courses, consumption by rats, cats, and humans is enhanced compared with intake of the same food, even if the single food is highly preferred (Mugford, 1977; Rolls, 1979; Rolls, Rowe, Rolls, 'Kingston, Megson, \& Gunary, 1981). Using luncheons of sandwiches or yogurt, Rolls et al. reported that variety enhanced feeding in females more than in males. They also speculated that variety would stimulate consumption if different foods were presented simultaneously, as well as under conditions of successive presentation. In the present study, this prediction was tested in groups of male and female students.

\section{METHOD}

\section{Subjects}

Ten male and 12 female students at North Dakota State University participated in the experiment as part of a course requirement in the psychology of motivation class in which they were enrolled. Although weights and heights were not obtained, none of the subjects appeared to be grossly overweight or underweight. Within each sex, the subjects were randomly assigned to the one-flavor or three-flavor conditions.

\section{Procedure}

About 1 week prior to the experiment, the students filled out a brief questionnaire designed to assess their liking for ice cream in general and frequency of consumption. They also rated their liking of several different flavors of ice cream on a 9 -point scale $(1=$ dislike, $9=$ like very much). Eighteen of the 22 subjects reported that they liked ice cream fairly well or very much, and there were no group differences on this variable. Likewise, self-reported frequency of consumption was similar for the four groups.

On the evening of the experiment, the subjects were asked to "eat a normal dinner but skip dessert." Roughly half of the subjects reported to the laboratory at $1900 \mathrm{~h}$ one evening; the remainder were tested on the following evening. The experiment was conducted in a large seminar room, with all of the subjects seated about a table. The experimenter explained that the subjects were to eat as much ice cream as they wanted and that some people would be permitted to eat one flavor and others three flavors. Four flavors (chocolate, vanilla, strawberry, and chocolate chip; Bridgeman Dairy Company, Minneapolis, Minnesota) were available; each contained $1.11 \mathrm{cal} / \mathrm{ml}$. Depending on the condition they were assigned to, the subjects selected the one or three flavors they liked best from those available. For the first serving, the experimenter scooped as much ice cream as the subject requested into a dish, weighed the dish, and presented it to the subject. For subjects in the three-flavor condition, the first serving contained about one scoop of each flavor. When the subject had eaten all he wished, the experimenter reweighed the dish. At the same time, the experimenter inquired if the subject wanted more ice cream, attempting to communicate that the subject could eat as much as he wished by statements such as "Sure you don't want some more?"

\section{RESULTS}

As seen in Table 1, females in the three-flavor condition consumed more than twice as much ice cream as females in the one-flavor condition $[t(10)=3.06$, $\mathrm{p}<.025]$. In contrast, dietary variety did not affect intake by males, who tended to consume large amounts under both conditions. Despite the high average intake by males in both conditions, the sex difference in consumption was not significant, because of the highly variable intake by males. Two males, one in each condition, ate more than $650 \mathrm{~g}$ of ice cream.

Table 1

Ice Cream Consumption

\begin{tabular}{|c|c|c|c|c|c|c|}
\hline & \multirow{2}{*}{$\begin{array}{c}\text { Total } \\
\mathbf{N}\end{array}$} & \multirow{2}{*}{$\begin{array}{c}\mathrm{N}(>1 \\
\text { Serving) }\end{array}$} & \multicolumn{2}{|c|}{ Rating } & \multicolumn{2}{|c|}{$\begin{array}{c}\text { Amount Con- } \\
\text { sumed (in Grams) }\end{array}$} \\
\hline & & & Mean & SEM & Mean & SEM \\
\hline & \multicolumn{6}{|c|}{ One Flavor } \\
\hline Males & 5 & 3 & 8.4 & .6 & 270.0 & 105.0 \\
\hline \multirow[t]{2}{*}{ Females } & 6 & 1 & 8.5 & .4 & 82.5 & 14.1 \\
\hline & \multicolumn{6}{|c|}{ Three Flavors } \\
\hline Males & 5 & 3 & 8.2 & .4 & 277.6 & 109.1 \\
\hline Females & 6 & 3 & 8.2 & .4 & 181.3 & 29.6 \\
\hline
\end{tabular}

Note-Ratings are for the single flavor actually consumed by subjects in the one-flavor condition and for the best liked flavor in the three-flavor condition. 
The stimulatory effect of variety on intake in females arose partly because of greater intake per helping and partly because females in the three-flavor condition were more likely to return for additional servings. Males in the two conditions were equally likely to consume additional servings.

Preference ratings for the flavors actually consumed indicated that nearly all subjects liked the ice cream very well. Since the ratings by the females in the one-flavor condition were actually slightly higher than the best liked flavor for the females in the three-flavor condition, the stimulating effect of variety cannot have arisen because access to several different flavors increased the chance the subject would find a highly preferred flavor.

\section{DISCUSSION}

The present findings suggest that variety in a diet of very similar foods stimulates appetite in human females, but not in males. The data confirm the sex difference in the effect of variety described by Rolls et al. (1981) and extend these results to a situation in which different foods are simultaneously available.

Several different explanations of the sex difference in the effect of dietary variety can be entertained. First, it might be argued that demand characteristics of the test situation are largely responsible for the effect. To explain the sex difference in these terms, one must assume that females are more likely to try to confirm the experimental hypothesis and that they correctly detect it from the cues in the situation. Rolls et al. (1981) used a within-subjects design that is more vulnerable to the influence of demand characteristics, but they took pains to keep the subjects unaware that their intake was being monitored. In the present study, the subjects were quite aware that consumption was being measured, but each subject served in only one of the flavor conditions. As the group testing situation included subjects of both flavor conditions, the opportunity to learn the purpose of the study was present in the experimental context. However, considering the magnitude of the effect of variety in females as well as the small sample size, to explain the results in terms of demand characteristics one must assume that nearly all of the female subjects correctly guessed the experimental hypothesis and behaved in a way that would support it. One must further assume that the males either did not detect the experimental purpose or they did not adjust their behavior to confirm the prediction. While the present findings can be explained logically by sex differences in response to demand characteristics, it is difficult to imagine that all of the assumptions required by this explanation were actually met.

A more promising hypothesis about the sex difference in the effect of variety rests on the fact that the social influences that restrain eating in our culture operate more powerfully for females than for males. Females score higher on the restrained eating scale and express more concern about dieting, weight, and food consumption than males (Klesges, Note 1). College age women of normal or less than normal weight are also more likely to judge themselves to be obese (Klesges, Note 2), which may be related to the much higher incidence of anorexia nervosa and bulimia among women (American Psychiatric Association, 1980; Slade \& Russell, 1973). Males, on the other hand, are less likely to be concerned about eating and its consequences. Prodigious displays of consumption of the sort exhibited by two of the males in this study are tolerated and even applauded by the norms that govern male behavior. In a public situation such as was employed in the present study, these sexually dimorphic rules about eating might be expected to exert stronger inhibitory influences on feeding by females. Previous work (Rolls et al., 1981) suggests that variety stimulates eating maximally near the end of the meal, when satiety mechanisms are already acting to inhibit intake. Thus, the disinhibitory effect of variety might be expected to be most powerful in female subjects with strong external inhibitions when they were consuming highly palatable desserts.

While an explanation based on cultural norms about eating seems to provide an adequate account of the sex difference in the effect of variety, the possible influence of biological factors should not be dismissed prematurely. Sex differences in saccharin and salt consumption (Krecek, 1973; Nance, 1976; Zucker, 1969), in eating of high-fat and high-sugar diets (Nance, Young, Bromiley, \& Gorski, 1977), and in the selection of protein-rich vs. carbohydrate-rich diets (Leshner \& Collier, 1973) have been reported in rats and have been shown to be hormone dependent. Variety in the diet stimulates eating in animals (Mugford, 1977; Rolls, 1979), and exposure to a varied diet of enticing supermarket foods leads to obesity in rats (Sclafani \& Springer, 1976). The possibility of a sex difference in response to variety in the diet has not been carefully studied in animals, and the available results are somewhat ambiguous. Male and female rats eating various supermarket foods gain equivalent amounts of weight, but the magnitude of obesity in males is less than in females if differences in the weight of controls feeding on ordinary laboratory chow are considered (Sclafani \& Gorman, 1977).

\section{REFERENCE NOTES}

1. Klesges, R. C. Predicting obesity and personality: Global versus specific measures? Manuscript submitted for publication, 1982.

2. Klesges, R. C. An objective analysis of distorted body image in a nonpatient population. Manuscript submitted for publication, 1982.

\section{REFERENCES}

American Psychiatric Association. Diagnostic and statistical manual of mental disorders (3rd. ed.). Washington, D.C: Author, 1980.

KRECEK, J. Sex differences in salt taste: The effect of testosterone. Physiology \& Behavior, 1973, 10, 683-688.

Leshner, A. I., \& Collier, G. The effects of gonadectomy on the sex differences in dietary self-selection patterns and carcass compositions of rats. Physiology \& Behavior, 1973, 11, 671676.

Mugrond, R. A. External influences on the feeding of carnivores. In M. R. Kare \& O. Maller (Eds.), The chemical senses and nutrition. New York: Academic Press, 1977.

NANCE, D. M. Sex differences in the hypothalamic regulation of feeding behavior in the rat. In A. H. Riesen \& R. F. Thompson (Eds.), Advances in psychobiology (Vol. 3). New York: Wiley, 1976.

Nance, D. M., Young, J. K., Bromiley, B., \& Gorski, R. A. The basis of sex differences in the regulation of feeding behavior in the rat. In Y. Katsuki, M. Sato, S. F. Takagi, \& Y. Oomura (Eds.), Food intake and chemical senses. Tokyo: University of Tokyo Press, 1977.

RoLls, B. J. How variety and palatability can stimulate appetite. Nutrition Bulletin, 1979, 5, 78-86.

Rolls, B. J., Rowe, E. A., Rolls, E. T., Kingston, B.,

Megson, A., \& Gunary, R. Variety in a meal enhances food intake in man. Physiology \& Behavior, 1981, 26, 215-221.

Sclafani, A., \& Gorman, A. N. Effects of age, sex and prior body weight on the development of dietary obesity in adult rats. Physiology \& Behavior, 1977, 18, 1021-1026.

Sclafani, A., \& SPRINGER, D. Dietary obesity in adult rats: 
Similarities to hypothalamic and human obesity syndromes. Physiology \& Behavior, 1976, 17, 461-471.

Slade, P., \& Russell, G. Experimental investigations of bodily perception in anorexia nervosa and obesity. Psychotherapy and Psychosomatic Medicine, 1973, 22, 359-363.
ZUCKER, I. Hormonal determinants of sex differences in saccharin preference, food intake, and body weight. Physiology \& Behavior, 1969, 4, 595-602.

(Received for publication February 2, 1982.) 